\title{
Olive oil phenolics: effects on DNA oxidation and redox enzyme mRNA in prostate cells
}

\author{
José L. Quiles ${ }^{1}$, Andrew J. Farquharson ${ }^{2}$, David K. Simpson ${ }^{2}$, Ian Grant ${ }^{2}$ and Klaus W. J. Wahle \\ ${ }^{1}$ Institute of Nutrition and Food Technology, Department of Physiology, University of Granada, C/Ramón y Cajal 4, 18071 \\ Granada, Spain \\ ${ }^{2}$ Rowett Research Institute, Greenburn Road North, Bucksburn, Aberdeen, AB21 9SB, UK
}

(Received 17 July 2001 - Revised 4 February 2002 - Accepted 8 April 2002)

\begin{abstract}
Hydroxytyrosol, tyrosol and caffeic acid effects on hydrogen peroxide-induced DNA damage, hydroperoxide generation and redox enzyme gene expression were studied in oxidative-stresssensitive human prostate cells (PC3). Hydroxytyrosol led to lower levels of hydroperoxides, DNA damage, and mRNA levels of classic glutathione peroxidase (GPx) for all the studied concentrations. Only hydroxytyrosol was effective at low concentrations $(10 \mu \mathrm{M})$. Tyrosol reduced DNA oxidation only at high $(>50 \mu \mathrm{M})$ concentrations and increased hydroperoxides, GPx and phospholipid hydroperoxide GPx mRNA levels. Caffeic acid elicited effects between those of the other two phenolics. Results indicate that hydroxytyrosol is the only significant antioxidant phenolic in olive oil and may be the major component accounting for its beneficial properties. Tyrosol appeared to exhibit pro-oxidant effects (only at high concentrations) and caffeic acid was neutral. Both number and position of hydroxyl groups appear to play a role in the cellular effects of hydroxytyrosol.
\end{abstract}

Olive oil: Phenolic compounds: DNA damage: Gene expression

Increasing evidence suggests that the beneficial effects of olive oil intake on human health can be ascribed not only to elevated oleic acid content (Mataix et al. 1998) but also to antioxidant properties of its minor components, including phenolic compounds (Quiles et al. 1999b; Visioli et al. 2000a).

Phenolic compounds are found not only in olive oil but also in many plant species where they are present at high concentrations in many components of the 'Mediterranean diet', including fruit and vegetables (Ho et al. 1992; Manna et al. 1997). The average consumption of phenols probably exceeds $1 \mathrm{~g} / \mathrm{d}$, sufficient to have nutritional relevance if they are bioactive (Manna et al. 1997). Interest in oliveoil phenols is increasing as a consequence of their reported antioxidant properties (Visioli et al. 1998a) and the reported health benefits of olive oil in man. For example, protection against LDL oxidation and inhibition of platelet aggregation by hydroxytyrosol, one of the main olive-oil phenols, has been reported (Visioli et al. 1998b). Hydroxytyrosol also attenuates the cytokine-induced up regulation of vascular adhesion molecules in human endothelial cells in culture, which would reduce the likelihood of atherogenesis in vivo (Farquharson et al. 1999). Apart from their anti-atherogenic properties, these non-essential dietary components appear to elicit promising anti-carcinogenic effects (Della Regione et al. 2000; Owen et al. 2000) and prevent the release of arachidonic acid from membrane phospholipids through their inhibition of phospholipase $\mathrm{A}_{2}$, thus reducing the production of chemotactic and inflammatory eicosanoids (Middleton \& Kandaswami, 1992). Additionally, they are also inhibitors of lipoxygenase and cyclo-oxygenase activity per se (Laughton et al. 1991). Excessive eicosanoid production, especially prostaglandin $E_{2}$, is a major factor in angiogenesis and increased cancer progression; inhibition of prostaglandin $E_{2}$ production attenuates progression, particularly of colon cancers (Karmali, 1987). Finally, the anti-carcinogenic activity of phenols may be due not only to their antioxidant properties but also to their ability to reduce the bioavailability of food carcinogens and to inhibit their metabolic activation (Stavric, 1994). Other non-antioxidant effects of phenolics on gene regulation or enzyme activities cannot be precluded (Farquharson et al. 1999).

Despite the reported beneficial effects of phenolic compounds on health, there is still a lack of knowledge regarding the mechanism of action of these natural compounds.

\footnotetext{
Abbreviations: cGPx, classic glutathione peroxidase; PHGPx, phospholipid hydroperoxide glutathione peroxidase.

* Corresponding author: Dr José L. Quiles, fax +34 958 248326, email jlquiles@ugr.es
} 
For example, it is not clear what their bioavailability is in man or on what intracellular targets they exert their antioxidant and cell-regulatory effects. Furthermore, the relationship between their chemical structure, their antioxidant properties and their specific regulatory effects on the intrinsic antioxidant enzymes and various cellular control mechanisms are not clear at present.

The aim of the present study was to investigate: (i) the role of three different phenolic compounds, hydroxytyrosol, tyrosol and caffeic acid, on the oxidative damage of lipids and DNA in a cell-line derived from human prostate epithelium (PC3), this cell line having been chosen because we have shown it to be very sensitive to oxidative stress; (ii) the effect of these phenolics on gene regulation (mRNA expression) of intrinsic antioxidant enzymes (classic glutathione peroxidase (cGPx; EC 1.11.1.9) and phospholipid hydroperoxide glutathione peroxidase (PHGPx; EC 1.11.1.12)) in PC3 cells. The three phenolics were chosen (Fig. 1) because of their similarity in structure.

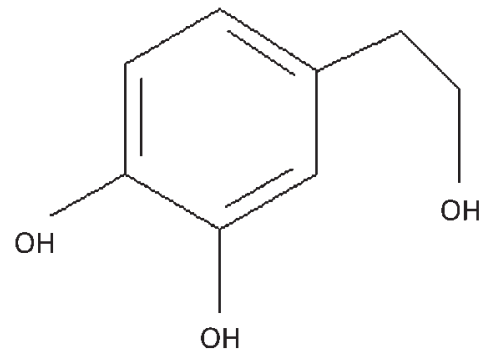

Hydroxytyrosol

(3,4-dihydroxyphenyl ethanol)

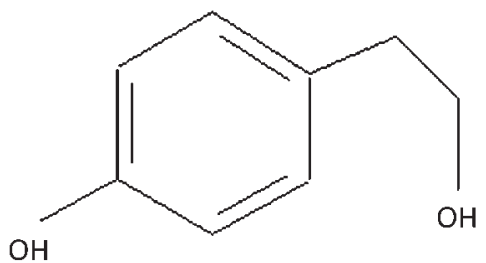

Tyrosol

(4-hydroxyphenyl ethanol)

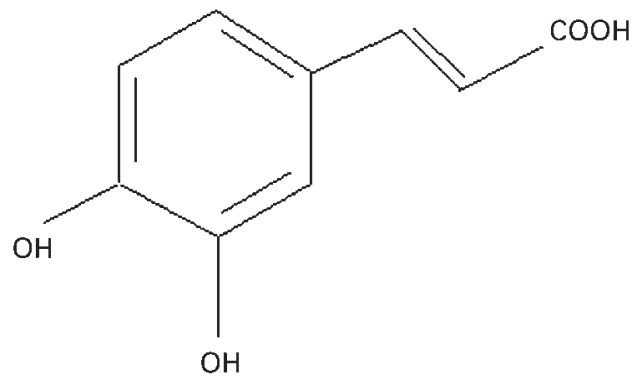

Caffeic acid

Fig. 1. Chemical structure of the three phenolic compounds used in the present study (hydroxytyrosol, tyrosol and caffeic acid).
Thus, hydroxytyrosol (3,4-dihydroxyphenyl ethanol), which is the main phenolic compound present in virgin olive oil $(70-80 \%$ of total phenolic fraction either in a free form or esterified as oleuropein; Baldioli et al. 1996), has an o-diphenolic structure and an ethylenic group. Tyrosol (4-hydroxyphenyl ethanol) has the same molecular structure as hydroxytyrosol but lacks the phenolic hydroxyl group. Caffeic acid has an $o$-diphenol structure but not an ethylenic group.

Understanding the underlying cell-regulatory mechanisms that are affected by these phenolic compounds may help to give a scientific basis to the reported health benefits of olive oil and the classical 'Mediterranean diet' as well as the structure-function relationship of phenolic compounds.

\section{Materials and methods}

\section{Cell culture and treatment}

PC3 human prostate cancer cells were grown in RPMI 1640 medium supplemented with $200 \mu \mathrm{g}$ streptomycin $/ \mathrm{ml}$, $200 \mathrm{IU}$ penicillin $/ \mathrm{ml}, 10 \%(\mathrm{w} / \mathrm{v})$ fetal calf serum and $100 \mu \mathrm{g}$ filter-sterile sodium pyruvate/ml. Cells were maintained in an atmosphere of $\mathrm{CO}_{2}-$ air $(5: 95, \mathrm{v} / \mathrm{v})$. Cells were passaged through subcultures by trypsinization at $0.05 \%$ and seeded at the concentration of $4 \times 10^{4}$ cells $/ \mathrm{ml}$. Cells were treated for $24 \mathrm{~h}$ with $10,50,100$ and $250 \mu \mathrm{M}$ 3,4-dihydroxyphenylethanol (hydroxytyrosol), 4hydroxyphenylethanol (tyrosol) or caffeic acid (see later for DNA oxidative-damage special conditions) by addition of the compounds to the medium in the form of 100-fold concentrated stock solutions of ethanol. All the cells were exposed to the same concentration of ethanol and these concentrations did not affect the mechanisms and end-points under investigation.

\section{Cytotoxicity assay by flow cytometry}

Propidium iodide was used in an exclusion experiment to assay the cytotoxicity of the various phenolics through the integrity of plasma membrane in the cells (Dengler et al. 1995). Propidium iodide fluoresces when it binds to DNA and is excluded from cells that have their plasma membrane integrity preserved. Consequently, the degree of fluorescence intensity correlates with the cytotoxic index of the compound being studied. After $24 \mathrm{~h}$ treatment, isolated cells were placed $\left(10^{6}\right)$ in a plastic tube and suspended in $1 \mathrm{ml}$ PBS. Propidium iodide $(20 \mathrm{ml})$ was added (final concentration, $2 \mu \mathrm{g} / \mathrm{ml}$ ) and cells were incubated for $5 \mathrm{~min}$ at room temperature in the dark before analysis. Flow cytometry was performed using a FACStar (Becton Dickinson, Mountain View, CA). Ar laser excitation was $50 \mathrm{~mW}$ at the $488 \mathrm{~nm}$ line. Red propidium-iodide fluorescence was detected above $620 \mathrm{~nm}$. At least 15000 cells (events) were analysed for each sample. Frequency distributions of propidium iodide concentration in the cells were obtained on a 4 decades fluorescence intensity scale (1024 channels) and descriptive statistics were performed. The median of the frequency distribution was chosen as representative of the propidium iodide level of the sample. 


\section{Oxidative DNA damage (the comet assay)}

The comet assay was used to measure DNA strand breaks in the cells (Collins et al. 1996). DNA damage was assessed in cells subjected to different phenolic supplementation treatments for $24 \mathrm{~h}$. Cells were then washed with PBS and divided into two equal portions. Each portion was treated for $5 \mathrm{~min}$ with $60 \mu \mathrm{M}-\mathrm{H}_{2} \mathrm{O}_{2}$ in incomplete medium to study the effect of the added phenolics on cell DNA-damage under acute conditions. Cells were also incubated for $5 \mathrm{~min}$ using only incomplete medium and no $\mathrm{H}_{2} \mathrm{O}_{2}$ stimulation in order to study the effects of the phenolics under baseline conditions. After isolation, cells were suspended in $1 \%(\mathrm{w} / \mathrm{v})$ low melting point agarose in $\mathrm{PBS}, \mathrm{pH} \mathrm{7.4,} \mathrm{and} \mathrm{pipetted} \mathrm{onto} \mathrm{microscope} \mathrm{slides}$ precoated with a layer of $1 \%(\mathrm{w} / \mathrm{v})$ normal melting point agarose (warmed to $37^{\circ} \mathrm{C}$ before use). The low melting point agarose was allowed to set at $4{ }^{\circ} \mathrm{C}$ for $5 \mathrm{~min}$ and then the slides were immersed in a lysis solution $(2.5 \mathrm{M}-$ $\mathrm{NaCl}, 100 \mathrm{~mm}$-EDTA, $10 \mathrm{~mm}$-Tris at $\mathrm{pH} 10,1 \%(\mathrm{v} / \mathrm{v})$ Triton X-100; Sigma, St Louis, MO, USA) at $4^{\circ} \mathrm{C}$ for $1 \mathrm{~h}$ to remove cellular proteins. Slides were then placed in an electrophoresis tank containing $0.3 \mathrm{M}-\mathrm{NaOH}$ and $1 \mathrm{~mm}-$ EDTA, pH 10 at $4{ }^{\circ} \mathrm{C}$ for $40 \mathrm{~min}$ to allow the separation of the two DNA strands (alkaline unwinding). Electrophoresis was performed at $25 \mathrm{~V}, 300 \mathrm{~mA}$ for $30 \mathrm{~min}$. The slides were then washed three times for $5 \mathrm{~min}$ each with a neutralizing solution $(0.4 \mathrm{M}$-Tris, $\mathrm{pH} 7.5)$ at $4^{\circ} \mathrm{C}$ before staining with $1 \mathrm{mg}$ 4,6-diamidino-2-phenylindole/ml.

4,6-Diamidino-2-phenylindole-stained nucleoids in each gel were examined under a u.v. microscope with an excitation filter of $435 \mathrm{~nm}$ and a magnification of 400. Analysis (blind) was performed using a charged couple device camera and Komet 3.0 image analysis program (Kinetic Imaging Ltd, Liverpool, UK). The percentage of DNA in the tail (mean of 100 comets per gel) is taken as a measure of DNA break frequency. The comet-like DNA formations were placed into five arbitrary classes $(0,1,2,3$ and 4) according to the extent of DNA damage represented by a comet-like 'tail'. Each comet was assigned a value according to its class and the overall score for 100 comets ranged from 0 (100\% of comets being class 0$)$ up to 400 (100\% of comets in class 4$)$.

\section{Determination of lipid peroxidation (hydroperoxides)}

The ferrous oxide-xylenol orange method was used for determining hydroperoxides in the cells according to the principle of the rapid peroxide-mediated oxidation of $\mathrm{Fe}^{2+}$ to $\mathrm{Fe}^{3+}$ under acidic conditions (Jiang et al. 1991). After treatment with the different phenolic compounds, rubberpoliceman isolated cells were incubated at $37^{\circ} \mathrm{C}$ for $30 \mathrm{~min}$ with the reagent in a water shaking bath. After centrifugation ( $2000 \mathrm{~g}$ for $5 \mathrm{~s}$ ) the supernatant fractions were monitored at $560 \mathrm{~nm}$ using cumene hydroperoxide as standard.

\section{Classic glutathione peroxidase and phospholipid hydroperoxide glutathione peroxidase $m R N A$ levels}

Total RNA was extracted by the acid guanidinium thiocyanate-phenol-chloroform procedure of Chomczynski \&
Sacchi (1987) and assessed by the $A_{260}: A_{280}$ absorbance ratio. RNA species were then separated by electrophoresis through a denaturing $2.2 \mathrm{M}$-formaldehyde, $1.2 \%(\mathrm{w} / \mathrm{v})$ agarose gel and transferred to a nylon membrane by capillary blotting. RNA was fixed to the membrane by exposure to u.v. light and the membranes were stored dry until required. Membranes were pre-hybridized for at least $6 \mathrm{~h}$ at $42^{\circ} \mathrm{C}$ with $0.1 \mathrm{mg}$ denatured salmon sperm DNA/ml in $50 \%(\mathrm{v} / \mathrm{v})$ formaldehyde, $10 \%(\mathrm{w} / \mathrm{v})$ dextran sulfate, $0.2 \%(\mathrm{w} / \mathrm{v})$ bovine serum albumin, $0 \cdot 2 \%(\mathrm{w} / \mathrm{v})$ polyvinylpyrrilidone, $0.2 \%(\mathrm{w} / \mathrm{v})$ Ficoll, $0.1 \%(\mathrm{w} / \mathrm{v})$ sodium pyrophosphate, $1 \%(\mathrm{w} / \mathrm{v}) \mathrm{SDS}$ and $50 \mathrm{~mm}-$ Tris- $\mathrm{HCl}, \mathrm{pH} 7 \cdot 5$. The DNA probes $(30 \mathrm{ng})$ were labelled with $\left[{ }^{32} \mathrm{P}\right] \mathrm{dcy}$ tosine triphosphate by random priming and hybridization carried out at $42^{\circ} \mathrm{C}$ for $24 \mathrm{~h}$ as described previously (Bermano et al. 1996). Membranes were then washed to remove non-specifically-bound probe, had two washes in $2 \times$ saline-sodium citrate $(\mathrm{SSC}) \quad(1 \times \mathrm{SSC}=0.15 \mathrm{~mol} / 1$ $\mathrm{NaCl}-0.015 \mathrm{~mol} / \mathrm{l}$ sodium citrate) at room temperature for $5 \mathrm{~min}$, followed by two washes at $65^{\circ} \mathrm{C}$ for $1 \mathrm{~h}$ in either $1 \times \mathrm{SSC}, 1 \%(\mathrm{w} / \mathrm{v}) \mathrm{SDS}(\mathrm{cGPx}$ and PHGPx) or $0.2 \times \mathrm{SSC}, 1 \%(\mathrm{w} / \mathrm{v}) \mathrm{SDS}(18 \mathrm{~S}$ rRNA) and a final wash in $0.1 \times \mathrm{SSC}$ at room temperature. Specific hybridization was then detected by electronic autoradiography using a Camberra Packard Instantimager (Packard, Pangbourne Berks, UK). After analysis membranes were washed in $0.1 \%(\mathrm{w} / \mathrm{v}) \mathrm{SDS}$ for $5-10 \mathrm{~min}$ at $95^{\circ} \mathrm{C}$ before rehybridization to other probes.

Quantification of the bound probe was carried out using the Instantimager (Packard) and results for each probe expressed per unit of hybridization achieved with the $18 \mathrm{~S}$ rRNA probe. This allowed correction for any variation between loading of RNA on the gel or transfer to the nylon membrane.

\section{cDNA probes and chemicals}

3,4-Dihydroxyphenyl ethanol (hydroxytyrosol) was purchased from Cayman Chemical Company, Ann Arbor, MI, USA; 4-hydroxyphenyl ethanol (tyrosol) was purchased from Avocado Research Chemicals, Heysham, Lanc., UK. Propidium iodide was obtained from Molecular Probes, Europe, Leiden, Netherlands; cDNA probes for cGPx, PHGPx and 18S rRNA were a gift from Professor John Hesketh, Newcastle University, UK. All other products and reagents were of the highest grade available from commercial sources.

\section{Statistical analysis}

Results are presented as mean values with their standard errors for four experiments. Comparison of mean values between groups was assessed by one-way ANOVA followed by a post hoc Duncan's test. Previously, all variables were tested for normal and homogeneous variance by Levene test. When a variable was found not normal, it was log-transformed and reanalysed. $P$ values of less than 0.05 were considered significant. Data were analysed using SPSS statistical software package (SPSS for Windows, 9.0.1, 1999; SPSS Inc., Chicago, IL, USA). 


\section{Results \\ Cell viability and cytotoxicity}

The flow cytometry study of propidium iodide incorporation and exclusion did not show any differences in cell viability among PC3 cells treated with hydroxytyrosol, caffeic acid or tyrosol at the different concentrations with regard to the control (data not shown). This shows that even at pharmacological concentrations these phenolics do not appear to be cytotoxic.

\section{DNA oxidative damage (comet assay)}

Control, non-stimulated cells showed the lowest values of DNA damage (analysed by the comet assay) and this was taken as the $100 \%$ value (Fig. 2). No differences with regard to control were found for PC3 cells in the absence of $\mathrm{H}_{2} \mathrm{O}_{2}$ when treated with different concentrations of hydroxytyrosol, tyrosol and caffeic acid (values ranged from 88 (SEM 15) to 115 (SEM 22)) (data not shown). Cells without added phenolics, but treated with $60 \mu \mathrm{M}-$ $\mathrm{H}_{2} \mathrm{O}_{2}$, had a 12-fold increase in DNA damage compared with control cells. Fig. 2 also shows the level of oxidative damage in the DNA of cells stimulated with $60 \mu \mathrm{M}-\mathrm{H}_{2} \mathrm{O}_{2}$ for $5 \mathrm{~min}$ analysed by the comet assay. DNA damage was reduced dramatically in cells with increasing concentrations of hydroxytyrosol and incubated with $\mathrm{H}_{2} \mathrm{O}_{2}$. Decreased damage was proportional to the concentration of the phenolic compound, with the lowest damage observed for $250 \mu \mathrm{M}$-hydroxytyrosol. For tyrosol, only 100 and $250 \mu \mathrm{M}$ concentrations were able to decrease DNA damage of peroxide-treated cells but this decrease was less than that found with the same concentrations of hydroxytyrosol-treated cells. Cells treated with 50, 100 and $250 \mu \mathrm{M}$-caffeic acid also exhibited a dose-dependent decrease in DNA damage in PC3 cells treated with $\mathrm{H}_{2} \mathrm{O}_{2}$; the caffeic acid effectiveness was higher than tyrosol but lower than hydroxytyrosol.

\section{Lipid peroxidation (hydroperoxides generation)}

Fig. 3 depicts the hydroperoxide production in PC3 cells treated for $24 \mathrm{~h}$ with hydroxytyrosol, tyrosol or caffeic acid. Irrespective of the concentration used (10, 50, 100 or $250 \mu \mathrm{M}$ ) cells treated with hydroxytyrosol produced significantly less hydroperoxides than control cells $(100 \%)$ and those treated with tyrosol or caffeic acid; increasing concentrations of hydroxytyrosol above the $10 \mu \mathrm{M}$ level did not result in further reductions in peroxides. Tyrosoltreated cells produced the highest proportion of hydroperoxides and levels were generally greater than in controls; again, values were independent of phenolic concentrations. Caffeic acid-treated cells produced a similar proportion of hydroperoxides as control cells; the proportion was greater than that produced by cells treated with hydroxytyrosol and lower than those treated with tyrosol and was independent of the phenolic concentrations.

\section{Classic glutathione peroxidase and phospholipid hydroperoxide glutathione peroxidase mRNA levels}

The stable transcription rate for cGPx mRNA is shown in Fig. 4. Hydroxytyrosol-treated cells exhibited significantly lower mRNA abundance than control cells (100\%) at all concentrations. The 50, 100 and $250 \mu \mathrm{M}$ treatments elicited similar but lower effects than that of the $10 \mu \mathrm{M}$ treatment. For tyrosol-treated cells, all concentrations except $10 \mu \mathrm{M}$ elicited a higher mRNA abundance than control cells and

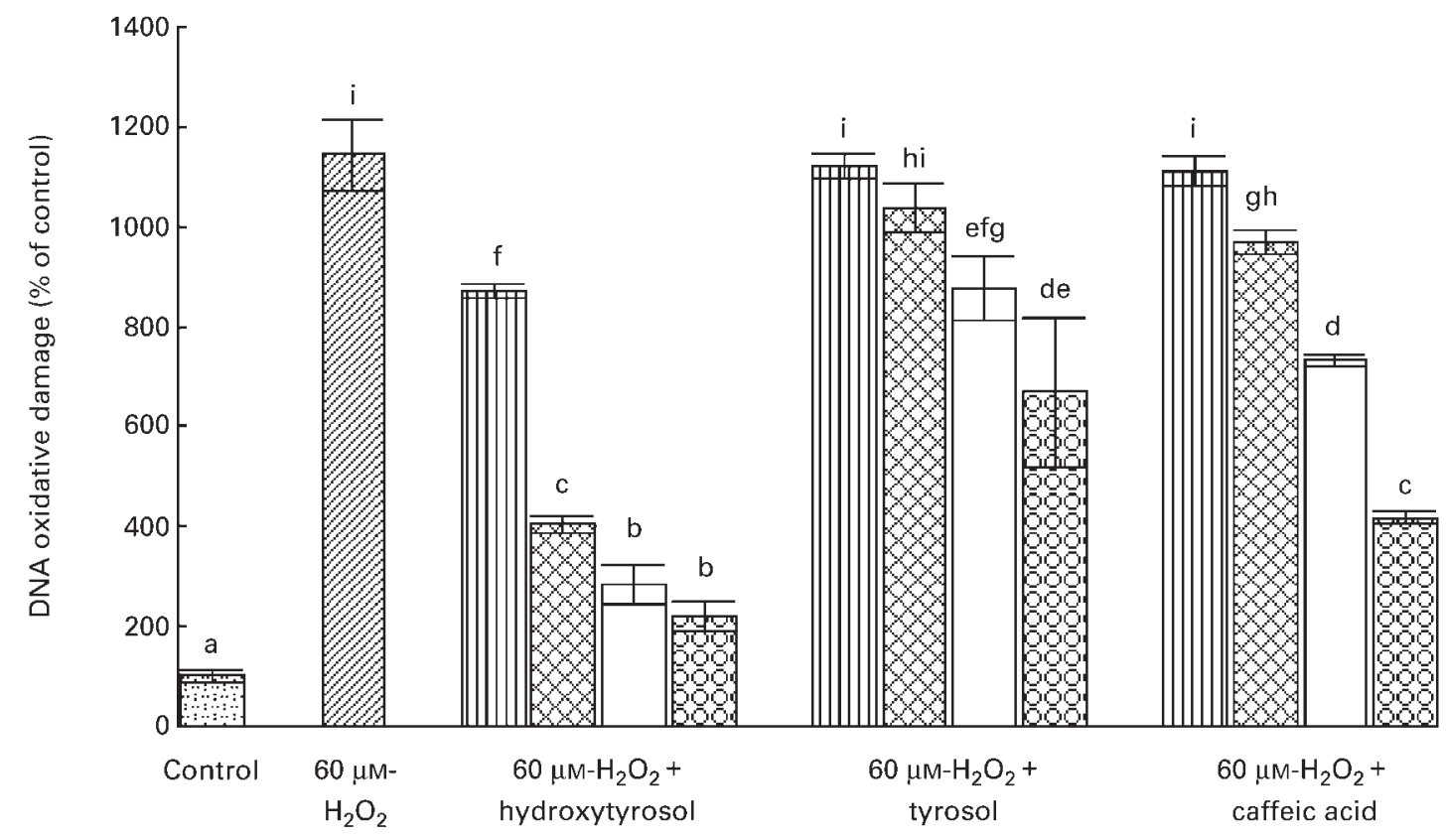

Fig. 2. Effect of $24 \mathrm{~h}$ incubation with different concentrations of hydroxytyrosol, tyrosol and caffeic acid on DNA oxidative damage in PC3 cells. (而), $10 \mu \mathrm{M}$; (网), $50 \mu \mathrm{M} ;(\square), 100 \mu \mathrm{M}$; (8g), $250 \mu \mathrm{m}$. Before being harvested, cells were treated for 5 min with $60 \mu \mathrm{M}-\mathrm{H}_{2} \mathrm{O}_{2}$. Results are mean values of four different experiments; standard errors of the mean are represented by vertical bars. Values with different superscripts are significantly different $(P<0.05)$ according to a one-way ANOVA followed by Duncan's test. 


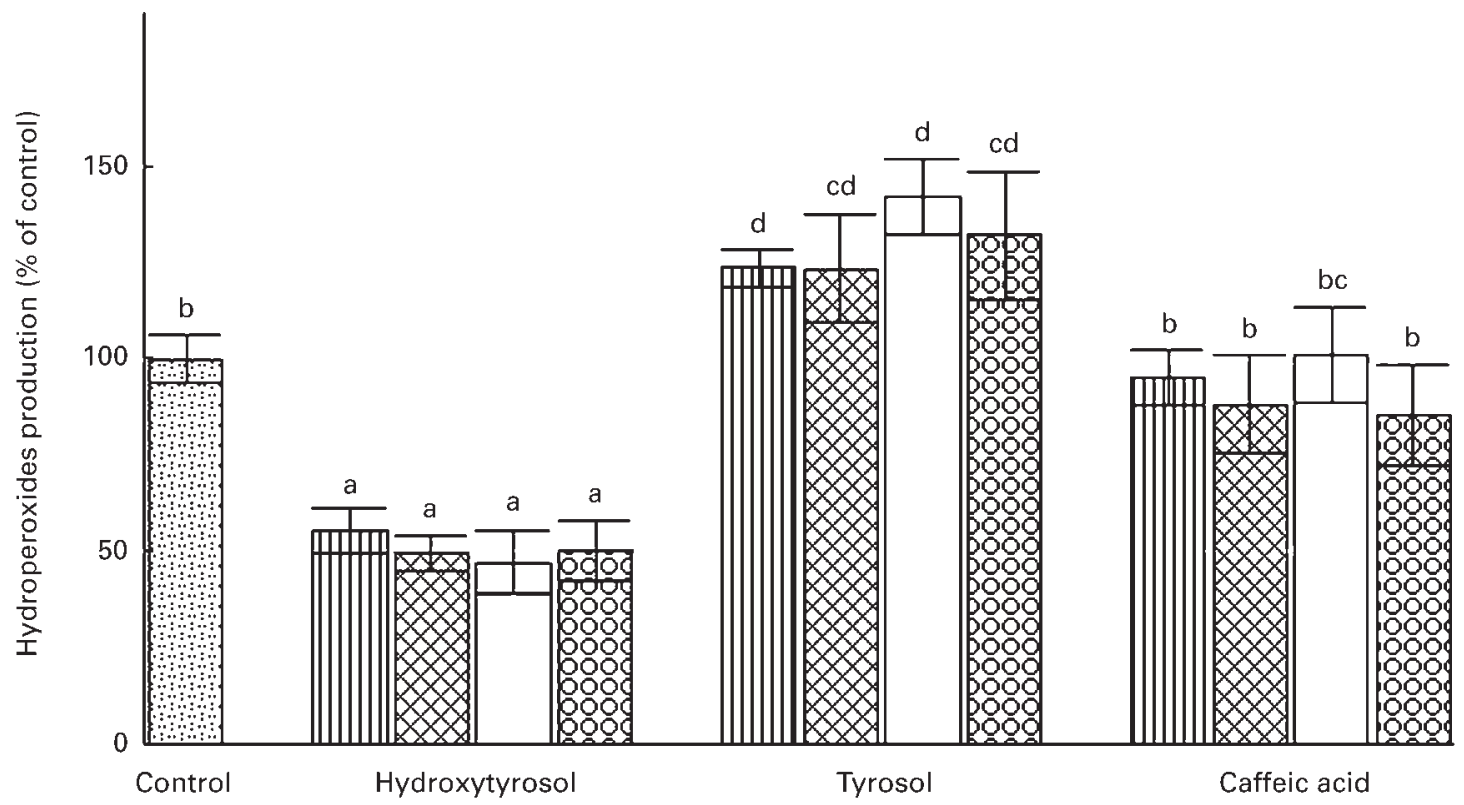

Fig. 3. Effect of $24 \mathrm{~h}$ incubation with different concentrations of hydroxytyrosol, tyrosol and caffeic acid on the production of lipid hydroperoxides in PC3 cells. (四), $10 \mu \mathrm{M}$; (网), $50 \mu \mathrm{M} ;(\square), 100 \mu \mathrm{M}$; (8g), $250 \mu \mathrm{M}$. Results are mean values of four different experiments; standard errors of the mean are represented by vertical bars. Values with different superscripts are significantly different $(P<0.05)$ according to a one-way ANOVA followed by Duncan's test.

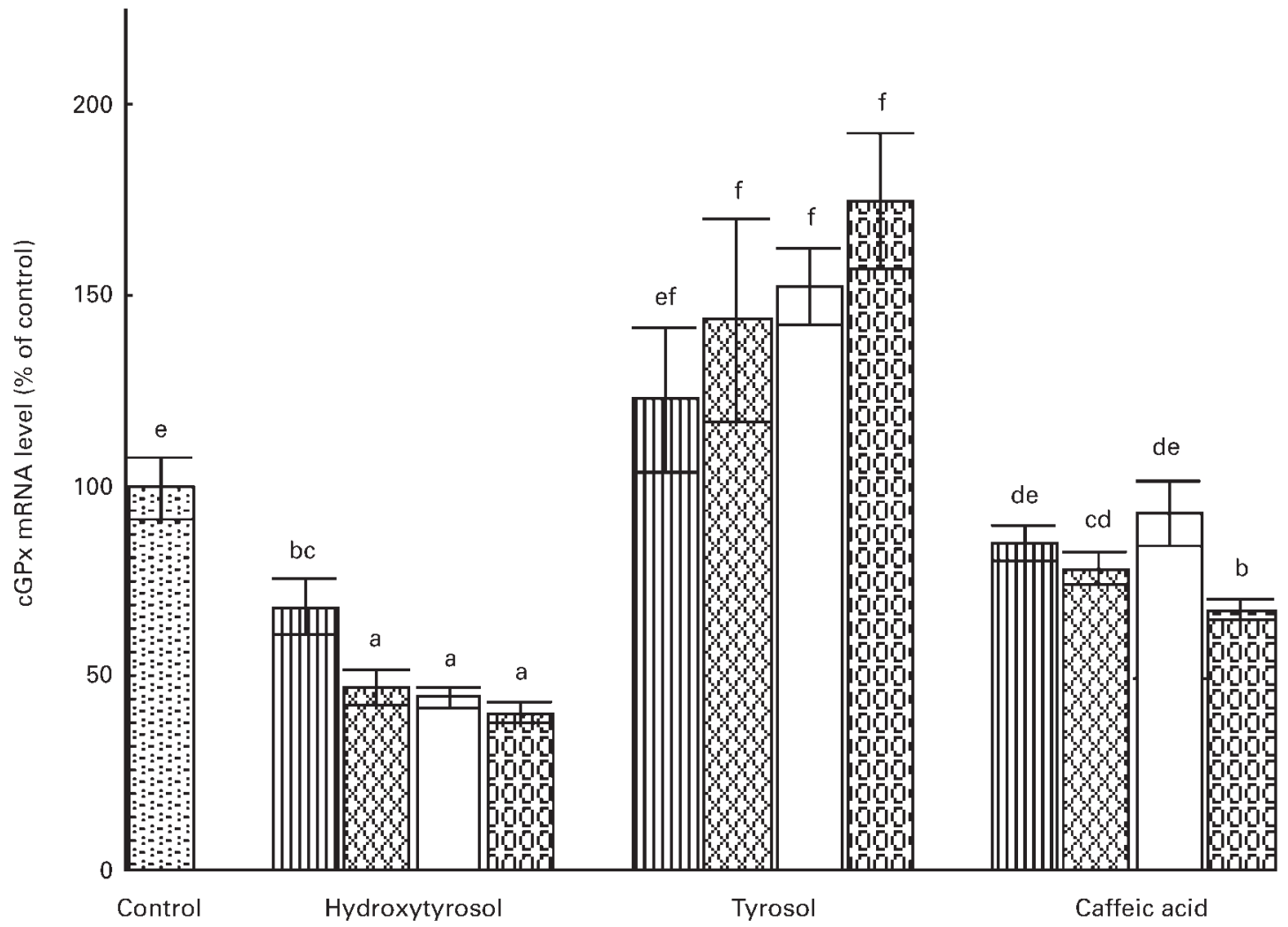

Fig. 4. Effect of $24 \mathrm{~h}$ incubation with different concentrations of hydroxytyrosol, tyrosol and caffeic acid on the relative mRNA levels of classic glutathione peroxidase (cGPx) in PC3 cells. (西), $10 \mu \mathrm{M}$; (ख), $50 \mu \mathrm{M} ;(\square), 100 \mu \mathrm{M}$; (8g), $250 \mu \mathrm{M}$. Results are mean values of four different experiments; standard errors of the mean are represented by vertical bars. Values with different superscripts are significantly different $(P<0.05)$ according to a one-way ANOVA followed by Duncan's test. 


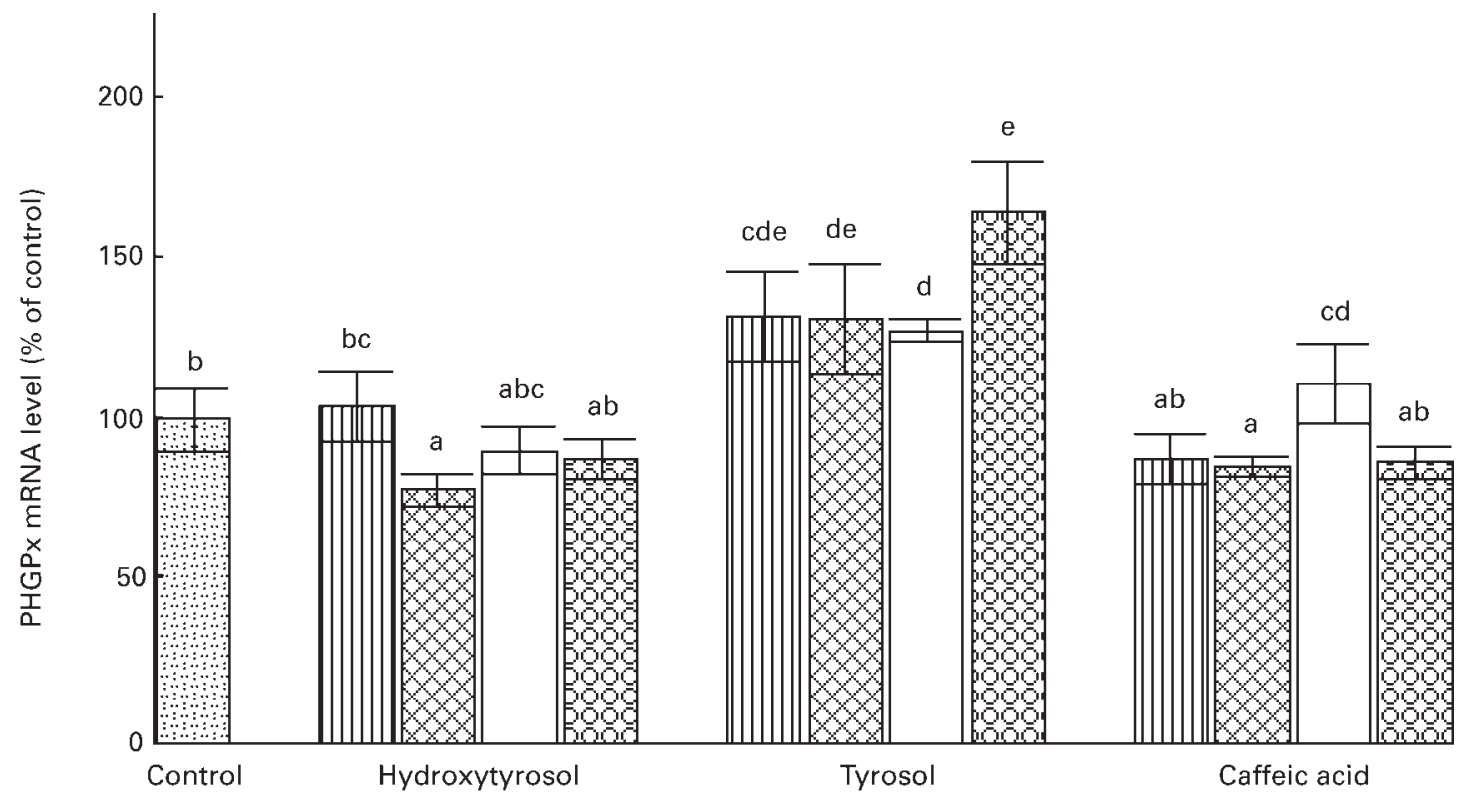

Fig. 5. Effect of $24 \mathrm{~h}$ incubation with different concentrations of hydroxytyrosol, tyrosol and caffeic acid on the relative mRNA levels of phospholipid hydroperoxide glutathione peroxidase (PHGPx) in PC3 cells. (而), $10 \mu \mathrm{M}$; (网), $50 \mu \mathrm{M}$; $\square$ ), $100 \mu \mathrm{M}$; (82), $250 \mu \mathrm{M}$. Results are mean values of four different experiments; standard errors of the mean are represented by vertical bars. Values with different superscripts are significantly different $(P<0.05)$ according to a one-way ANOVA followed by Duncan's test.

the increase was similar for the different concentrations. In the caffeic acid-treated cells, 10 and $100 \mu \mathrm{M}$ did not elicit changes in cGPx mRNA abundance compared with control cells, but 50 and $250 \mu \mathrm{M}$ concentrations elicited an attenuation of abundance compared with control cells; values were not as low as those observed with hydroxytyrosol.

Fig. 5 shows results for gene expression of PHGPx (mRNA) in cells treated with different concentrations of phenolics. With hydroxytyrosol treatments, only the $50 \mu \mathrm{M}$ concentration was able to elicit lower mRNA abundance than control cells (100\%). All other concentrations exhibited similar mRNA abundance to that in control cells. All tyrosol concentrations elicited a higher mRNA abundance than control cells; all concentrations resulted in a similar abundance except $250 \mu \mathrm{M}$, which gave the highest value. The results obtained after caffeic acid treatment of PC3 cells for $24 \mathrm{~h}$ were also not greatly different from control values. Concentrations of 10 and $250 \mu \mathrm{M}$ did not elicit any changes in mRNA abundance compared with control cells whilst $50 \mu \mathrm{M}$ elicited a slightly lower and $100 \mu \mathrm{M}$ a somewhat higher abundance compared with controls.

\section{Discussion}

It is increasingly apparent that the reported health benefits of dietary olive oil in the classical 'Mediterranean diet' may not be entirely due to the lipid component of the oil and that minor components such as mono-phenolics may play an important role (Mattson \& Grundy, 1985; Keys \& Keys, 1995; Willett, 1997; Mataix et al. 1998; Quiles et al. 1999a; Ramírez-Tortosa et al. 1999). Several studies have been conducted to elucidate the contribution of the phenolic components in virgin olive oil to the positive health effects attributed to the oil per se. However, to the best of our knowledge, no studies have been conducted that assess the efficacy of olive oil phenolics in regulating the gene expression of intrinsic antioxidant enzymes such as mRNA abundance of cGPx and PHGPx. Similarly, many questions relating to the intracellular site of action of these phenolics and their effectiveness in protecting cells against oxidative damage to DNA remain to be answered.

The present work describes the effectiveness of three olive oil phenolic derivatives with a similar structure (hydroxytyrosol, tyrosol and caffeic acid) that are present in virgin olive oil. They occur in variable concentrations (depending on virgin olive oil variety, geographical origin, harvest time, storage conditions, etc.), ranging from $2.6-27 \mathrm{mg} / \mathrm{kg}$ for hydroxytyrosol, $2.98-61.5 \mathrm{mg} / \mathrm{kg}$ for tyrosol and $0 \cdot 1-14.7 \mathrm{mg} / \mathrm{kg}$ for caffeic acid (Montedoro et al. 1992; Baldioli et al. 1996; Cinquanta et al. 1997; Owen et al. 2000). Although similar in structure, they differ in the number and position of their hydroxyl groups, which may be important in modulating the oxidative DNA damage and oxidant-induced gene expression of redox enzymes in human prostate cells elicited by $\mathrm{H}_{2} \mathrm{O}_{2}$. A recent study reported decreased tissue lipid peroxidation and increased tissue glutathione peroxidase activity in rabbits supplemented with olive oil in their diets, which suggested opposing anti- and pro-oxidant effects. These authors did not report changes in glutathione peroxidase gene expression (De la Cruz et al. 2000). These animal studies differ from the present cell studies in that the hydroxytyrosol in the current study elicited both decreased hydroperoxide formation and reduced glutathione peroxidase mRNA abundance, which appears more logical since cGPx is induced by oxidative stress. The increased 
cGPx observed in the animal studies compared with the decrease found in cells could be due to time-lapse differences between mRNA increase and the expression and the availability and durability of the enzyme protein.

The negligible DNA damage and lack of effect of the phenolics in cells that were not stimulated with $\mathrm{H}_{2} \mathrm{O}_{2}$ is normal considering that cells usually contain a variety of different antioxidant systems to protect their genetic material from damage by reactive oxygen species under physiological conditions (Sies, 1993). However, after induction of damage with $60 \mu \mathrm{M}-\mathrm{H}_{2} \mathrm{O}_{2}$ for $5 \mathrm{~min}$ the phenolics were able to protect cells from oxidative DNA damage. It was also evident from the results that the degree of protection afforded by these phenolics depended on their structure and the concentration used. Previous studies have clearly demonstrated a lack of protection against oxidative stress by tyrosol when compared with hydroxytyrosol in a wide variety of systems and oxidative conditions (Visioli \& Galli, 1998; Manna et al. 1999). However, there are no comparisons in the literature between hydroxytyrosol, tyrosol and other phenolics with regard to oxidative DNA damage and the regulation of redox enzymes at the level of gene transcription in human prostate cells. The present study showed that hydroxytyrosol effectively protected prostate cells against the DNA damaging effects of $\mathrm{H}_{2} \mathrm{O}_{2}$. Concentrations as low as $10 \mu \mathrm{M}$ resulted in a $23 \%$ reduction in damage whilst the highest concentration $(250 \mu \mathrm{M})$ resulted in an $80 \%$ reduction compared with $\mathrm{H}_{2} \mathrm{O}_{2}$-stimulated cells not treated with the phenolic.

To the best of our knowledge there are no definitive studies relating serum levels of olive oil phenolics to olive oil intake in human volunteers. This makes it difficult to estimate the likely physiological concentrations that might occur in plasma and tissues (and cells). However, Visioli et al. $(2000 a, b)$ reported that the absorption of hydroxytyrosol and tyrosol in human subjects (determined in $24 \mathrm{~h}$ urine samples) was $30-60 \%$ and $20-22 \%$ respectively of total intake. Owen et al. (2000) have estimated that virgin olive oil has 14.42 (SEM 3.01) mg hydroxytyrosol/kg and 27.45 (SEM 4.05) $\mathrm{mg}$ tyrosol $/ \mathrm{kg}$. These data must be carefully considered due to the high degree of variation among virgin olive oil samples (and keeping in mind that hydroxytyrosol is also present in the form of oleuropein), but it can be useful to calculate average concentrations in oils and thereby estimate average intakes in man. Thus, it is possible to assume concentrations of $81.7 \mu \mathrm{M}$ hydroxytyrosol in virgin olive oil and $175.5 \mu \mathrm{M}$ tyrosol. If the highest degree of absorption proposed by Visioli et al. $(2000 a, b)$ is considered, then up to $49 \mu \mathrm{M}$ hydroxytyrosol and $38.6 \mu \mathrm{M}$ tyrosol from virgin olive oil might be absorbed. The 10, 50 and even $100 \mu \mathrm{M}$ concentrations of phenolics used in the present study are probably within the physiological range, but the $250 \mu \mathrm{M}$ probably exceeds this range and could be regarded as being in the pharmacological range. This would also pertain to some of the published studies in vitro in which concentrations of 500 and $1000 \mu \mathrm{M}$ phenolics are used (for example, Petroni et al. 1997; Deiana et al. 1999). It is not known to what extent the phenolics present in olive oil can accumulate in different tissues. This could result in localized variations in their concentration, which would not reflect their plasma concentrations.

In the case of tyrosol, only $100 \mu \mathrm{M}$ with a $23 \%$ of reduction of the damage and $250 \mu \mathrm{M}$ with a $40 \%$ of reduction was able to protect DNA from $\mathrm{H}_{2} \mathrm{O}_{2}$-damage. Caffeic acid reduction of DNA damage was intermediate between that elicited by hydroxytyrosol and by tyrosol (i.e. 15,35 and $63 \%$ of reduction for 50, 100 and $250 \mu \mathrm{M}$ dosages respectively).

Functional differences between hydroxytyrosol and tyrosol have been attributed to the presence of only a single hydroxyl group in tyrosol compared with two of these groups present in hydroxytyrosol (Manna et al. 1999). Masella et al. (1999) suggests that the phenol chemical structure considerably influences the antioxidant activity as a consequence of both steric factors and those related to position and type of functional groups on the phenol ring. These authors stated that the antioxidant activity of biophenols depends mainly on the number of hydroxyl groups in the molecule. They also suggested that insertion of an ethylenic group between a phenyl ring and the carboxylate group ensured greater H-donating ability and subsequent radical stabilization. These considerations are in agreement with the present functional results in relation to the structures of hydroxytyrosol, tyrosol and caffeic acid. Hydroxytyrosol has two hydroxyl groups and an ethylenic group and exhibited the most significant antioxidant and gene regulatory effects. Tyrosol has the ethylenic group but only a single 4-hydroxyl group and caffeic acid has two hydroxyl groups $(3,4 \mathrm{OH})$ but no ethylenic group. Clearly, all three hydroxyl groups together are important for activity with the 3-hydroxy playing a key role in antioxidant function.

The efficacy of some plant-derived phenolics as inhibitors of mutational and precarcinogenic events in biological systems has been reported (Newmark, 1987) and Deiana et al. (1999) observed that hydroxytyrosol protected neuronal hybridoma cells against the peroxynitrite-dependent nitration of tyrosine and DNA damage by peroxynitrite in vitro. These beneficial effects of hydroxytyrosol against oxidation of DNA and its general antioxidant properties are confirmed and extended in the present study and are further augmented by the inhibitory effects on redox enzyme gene expression. The lower effectiveness of caffeic acid and the promotion of oxidative stress by tyrosol probably relates to their specific structure (see earlier). However, since hydroxytyrosol is absorbed to a greater extent than other virgin olive oil phenolics (Visioli et al. 2000b) and has the highest antioxidant activity, it is likely that its antioxidant and redox inhibitory effects will predominate. It cannot, however, be precluded that the other phenolics contribute to the beneficial properties of this dietary fat through non-antioxidant mechanisms (Sies, 1993), especially after recent studies confirming their absorption and availability to tissues (Manna et al. 2000; Visioli et al. 2000b).

In order to test the antioxidant capacity of our phenolic molecules we also determined a marker of lipid peroxidation in the cells as the levels of lipid hydroperoxides. In contrast to what happened with DNA damage, baseline conditions were enough to promote differences in lipid 
peroxidation. It has previously been demonstrated that under normal conditions, conventional cell culture media may promote oxidative stress because of their antioxidant deficiencies (Leist et al. 1996). Present results clearly show that hydroxytyrosol-treated cells produced $50 \%$ less hydroperoxide than control cells, irrespective of hydroxytyrosol concentrations. This lack of effect of phenolic dose-response effect on hydroperoxide formation was also found for tyrosol and caffeic acid. The pro-oxidant and antioxidant effects of tyrosol and hydroxytyrosol respectively have been previously described using other models and other markers of lipid peroxidation (Manna et al. 1997). No data from experiments with caffeic acid have been reported to date and at the present moment it is not possible to explain the absence of a concentration effect of these phenolics on hydroperoxide formation in the PC3 cells.

As a part of the test to study the putative antioxidant capacity of the assayed phenolic compounds, we studied the relative mRNA abundance (gene expression) of cGPx and PHGPx in prostate cells treated with the earlier-mentioned molecules. The attention has been focused on these antioxidant enzymes because of their particular subcellular distribution. cGPx is present in cytosol and the mitochondrial matrix, i.e. hydrophilic environments (Halliwell \& Gutteridge, 1999). PHGPx is a monomeric protein of relative molecular mass 19000 present in cell membranes that can reduce esterified fatty acid and cholesterol hydroperoxides. It can act upon these oxidized fatty acids directly within membranes and lipoproteins (unlike cGPx), reducing them to alcohols (Arai et al. 1999). Because of their regulation by oxidative stress, these enzymes may help us to elucidate the antioxidant properties of the olive oil phenolics and, very importantly, to elucidate their site of action.

As it happened for the lipid peroxidation experiment, baseline conditions were enough to produce differences in terms of RNA transcription for the assayed enzymes. Fig. 4 shows hydroxytyrosol produced less expression of cGPx than caffeic acid and especially than tyrosol. As for hydroperoxides, all the dosages (except $10 \mu \mathrm{M}$ for hydroxytyrosol and $250 \mu \mathrm{M}$ for caffeic acid) produced similar levels. The present findings clearly show that cells treated with hydroxytyrosol were more protected against oxidative stress than control cells or those treated with either tyrosol or caffeic acid and the response was more dependent on the chemical structure than on the dosage. Hydroxytyrosol reduced cGPx mRNA abundance, which correlated with the lowest level of hydroperoxides indicating a high degree of protection of DNA from oxidative damage. Neither hydroxytyrosol nor caffeic acid affected PHGPx mRNA abundance but tyrosol produced a small increase $(15 \%)$ in expression compared with control cells. This indicates that the phenolics affected cGPx mRNA to a greater extent than PHGPx mRNA, which may reflect differential regulation of the specific genes by these phenolics. These findings relating to the differential regulation of cGPx and PHGPx transcription by olive oil phenolics are novel and are indicative of specific nutrient-gene interaction, which could explain, at least in part, the beneficial effects of dietary olive oil. Furthermore, these findings suggest that these phenolics may elicit differences in the availability (amount) of cytosolic and membrane-bound redox enzymes (Manna et al. 2000).

In summary, results from the present study suggest that hydroxytyrosol and caffeic acid, two phenolic compounds present in the non-glyceride fraction of virgin olive oil, may act as antioxidants protecting DNA and lipids against oxidative damage. Hydroxytyrosol is more efficient than caffeic acid. However, tyrosol appears to be a pro-oxidant, albeit at high concentrations. In terms of chemical structure, differences in efficacy may be due to the presence of two hydroxyl groups in an $o$-position together with an ethylenic group in hydroxytyrosol. Caffeic acid, which only has two hydroxyl groups, has a lower antioxidant capability and finally, tyrosol, which has a single hydroxyl group plus the ethylenic group, has no antioxidant capacity and may even act as a pro-oxidant. Since hydroxytyrosol is the most active phenolic compound in virgin olive oil and has a higher degree of absorption than molecules such as tyrosol (Visioli et al. 2000b), it is conceivable that its antioxidant effects predominate. This would explain the reported beneficial effects on health of virgin olive oil consumption in Mediterranean countries. These phenolics are also able to modify the gene expression of cGPx more than of PHGPx suggesting that they act better under hydrophilic atmospheres than in membrane structures, which may be an important clue concerning the subcellular distribution of virgin olive oil phenolics.

Finally, 100 and $250 \mu \mathrm{M}$ hydroxytyrosol decreased cell proliferation with lower cell numbers observed (74.1 and $53.5 \%$ relative to the control, respectively), whereas tyrosol increased cell proliferation at 10 and $50 \mu \mathrm{m}$ tyrosol with higher cell number (148.6 and $171.5 \%$ relative to the control, respectively) being observed. This finding is indicative of increased apoptosis for the higher concentrations of hydroxytyrosol. Similar effects on cell proliferation were found by Della Regione et al. (2000) studying human myeloid leukemia HL60 cells. Thus, it is possible to speculate that 100 and $250 \mu \mathrm{M}$ hydroxytyrosol could be pro-apoptotic or at least anti-proliferative, which could affect tumour growth and development in vivo. By contrast, however, tyrosol could increase cell proliferation, which would be expected to enhance tumorigenesis. Interestingly (data not shown), the antiproliferative effects elicited by hydroxytyrosol in oxidative-stress sensitive PC3 cells were not found in less sensitive non-cancer prostate cells (PNT2). The relevance of these findings to prostate cancer and its prevention or amelioration is not clear at present and requires further study with emphasis on the expression of apoptotic genes and cell death per se.

\section{Acknowledgements}

J.L.Q. was supported by the University of Granada, Spain (Becas de Perfeccionamiento de Doctores Programme). D.K.S. was supported by a grant from World Cancer Research Fund (WCRF) and the other authors were supported by the Scottish Executive Rural and Agricultural Department (SERAD). 


\section{References}

Arai M, Imai H, Koumura T, Yoshida M, Emoto K, Umeda M, Chiba N \& Nakagawa Y (1999) Mitochondrial phospholipid hydroperoxide glutathione preoxidase plays a major role in preventing oxidative injure to cells. Journal of Biological Chemistry 274, 4924-4933.

Baldioli M, Servili M, Perretti G \& Montedoro GF (1996) Antioxidant activity of tocopherols and phenolic compounds of virgin olive oil. Journal of the American Oil Chemists Society 73, 1589-1593.

Bermano G, Arthur JR \& Hesketh JE (1996) Selective control of cytosolic glutathione peroxidase and phospholipid hydroper oxide glutathione peroxidase mRNA stability by selenium supply. FEBS Letters 387, 157-160.

Chomczynski P \& Sacchi N (1987) Single-step method of RNA isolation by acid guanidinium thiocyanate-phenol-chloroform extraction. Analytical Biochemistry 162, 156-159.

Cinquanta L, Esti M \& La Notte E (1997) Evolution of phenolic compounds in virgin olive oil during storage. Journal of the American Oil Chemists Society 74, 1259-1264.

Collins AR, Dusinska M, Gedik CM \& Stetina R (1996) Oxidative damage to DNA, Do we have a reliable biomarker? Environmental Health Perspectives 104, 465-469.

Deiana M, Aruoma OI, Bianchi M, Spencer J, Kaur H, Halliwell B, Aeschbach R, Banni S, Dessi MA \& Corongiu FP (1999) Inhibition of peroxynitrite dependent DNA base modification and tyrosine nitration by the extra virgin olive oil-derived antioxidant hydroxytyrosol. Free Radicals in Biology and Medicine 26, 762-769.

De la Cruz JP, Quintero L, Villalobos MA \& Sánchez de la Cuesta F (2000) Lipid peroxidation and glutathione system in hyperlipemic rabbits, influence of olive oil administration. Biochimica Biophysica Acta 1485, 34-44.

Della Regione F, Cucciolla V, Borriello A, Della Pietra V, Pontoni G, Racioppi L, Mana C, Galletti P \& Zappia V (2000) Hydroxytyrosol, a natural molecule occurring in olive oil, induces cytochrome c-dependent apoptosis. Biochemical and Biophysical Research Communications 278, 733-739.

Dengler WA, Schulte J, Berger DP, Mertelsmann R \& Fiebig HH (1995) Development of a propidium iodide fluorescence assay for proliferation and cytotoxicity assays. Anticancer Drugs 6, 522-532.

Farquharson A, Wu H-C, Grant I, Graf B, Choung J-J, Eremin O, Heys SD \& Wahle KWJ (1999) Possible mechanisms for the putative anti-atherogenic and anti-tumorigenic effects of conjugated polyenoic fatty acids. Lipids 34, S343.

Halliwell B \& Gutteridge JMC (1999) Free Radicals in Biology and Medicine, 3rd ed. New York, NY: Oxford University Press.

Ho CT, Lee CY \& Huang MT (1992) Phenolic Compounds in Foods and their Effects on Health, vol. I, Washington, DC: American Chemical Society.

Jiang ZY, Woollard ACS \& Wolff SP (1991) Lipid hydroperoxide measurement by oxidation of $\mathrm{Fe}^{2+}$ in the presence of xylenol orange. Comparison with the TBA assay and an iodometric method. Lipids 26, 853-856.

Karmali RA (1987) Eicosanoids in neoplasia. Preventive Medicine 16, 493-502.

Keys A \& Keys M (1995) How to Eat Well and Stay Well, the Mediterranean Way. New York, NY: Doubleday \& Co. Inc.

Laughton MJ, Evans PJ, Moroney MA, Hoult JRS \& Halliwell B (1991) Inhibition of mammalian 5-lipoxygenase and cyclooxygenase by flavonoids and phenolics dietary additives. Relationship to antioxidant activity and to iron ion-reducing ability. Biochemical Pharmacology 42, 1673-1681.

Leist M, Raab B, Maurer S, Rösick U \& Brigelius-Flohé R (1996) Conventional cell culture media do not adequately supply cells with antioxidants and thus facilitate peroxide-induced genotoxicity. Free Radicals in Biology and Medicine 21, 297-306.

Manna C, Della Regione F, Cucciolla V, Borriello A, D’Àngelo S, Galletti P \& Zappia V (1999) Biological effects of hydroxytyrosol, a polyphenol from olive oil endowed with antioxidant activity. In Advances in Nutrition and Cancer 2, pp. 115-130 [V Zappia, editor]. New York, NY: Plenum Publishers.

Manna C, Galleti P, Cucciolla V, Moltedo O, Leone A \& Zappia V (1997) The protective effect of the olive oil polyphenol (3,4-Dihydroxyphenyl)-ethanol counteracts reactive oxygen metabolite-induced cytotoxicity in Caco-2 cells. Journal of Nutrition 127, 286-292.

Manna C, Galletti P, Maisto G, Cucciolla V, D’Angelo S \& Zappia V (2000) Transport mechanism and metabolism of olive oil hydroxytyrosol in Caco-2 cells. FEBS Letters 470, 341-344.

Masella R, Cantafora A, Modesti D, Cardilli A, Gennaro L, Bocca A \& Coni E (1999) Antioxidant activity of 3,4-DHPEA-EA and protocateuuic acid, a comparative assessment with other olive oil biophenols. Redox Report 4, 113-121.

Mataix J, Quiles JL, Huertas JR, Battino M \& Mañas M (1998) Tissue specific interactions of exercise, dietary fatty acids, and vitamin $\mathrm{E}$ in lipid peroxidation. Free Radicals in Biology and Medicine 24, 511-521.

Mattson FH \& Grundy SM (1985) Comparison of dietary saturated, monounsaturated, and polyunsaturated fatty acids on plasma lipids and lipoproteins in man. Journal of Lipid Research 26, 194-202.

Middleton E \& Kandaswami C (1992) Effects of flavonoids on immune and inflammatory cell functions. Biochemical Pharmacology 43, 1167-1179.

Montedoro G, Servili M, Baldioli M \& Miniati E (1992) Simple and hydrolyzable phenolic compounds in virgin olive oil. 1. Their extraction, separation and quantitative and semiquantitative evaluation by HPLC. Journal of Agricultural and Food Chemistry 40, 1571-1576.

Newmark HL (1987) Plant phenolics as inhibitors of mutational and precarcinogenic events. Canadian Journal of Physiology and Pharmacology 65, 461-466.

Owen RW, Giacosa A, Hull WE, Haubner R, Spiegelhalder B \& Bartsch H (2000) The antioxidant/anticancer potential of phenolic compounds isolated from olive oil. European Journal of Cancer 36, 1235-1247.

Petroni A, Blasevich M, Papini N, Salami M, Sala A \& Galli C (1997) Inhibition of leukocyte leukotriene B4 production by an olive oil-derived phenol identified by mass spectrometry. Thrombosis Research 87, 315-322.

Quiles JL, Huertas JR, Mañas M, Battino M \& Mataix J (1999a) Physical exercise affects the lipid profile of mitochondrial membranes in rats fed with virgin olive oil or sunflower oil. British Journal of Nutrition 81, 21-24.

Quiles JL, Ramírez-Tortosa MC, Ibáñez S, González JA, Duthie GG, Huertas JR \& Mataix J (1999b) Vitamin E supplementation increases the stability and the in vivo antioxidant capacity of refined olive oil. Free Radical Research 31, S129-S135.

Ramírez-Tortosa MC, Urbano G, López-Jurado M, Nestares T, Gonzalez MC, Mir A, Ros E, Mataix J \& Gil A (1999) Extra-Virgin more than Refined Olive Oil Increases the Resistance of LDL to Oxidation in Free-Living Men with Peripheral Vascular Disease. Journal of Nutrition 129, 2177-2183.

Sies H (1993) Strategies of antioxidant defense. European Journal of Biochemistry 215, 213-219.

Stavric B (1994) Role of chemopreventers in human diet. Clinical Biochemistry 27, 319-332.

Visioli F, Bellomo G \& Galli C (1998a) Free radical-scavenging properties of olive oil polyphenols. Biochemical Biophysical Research Communications 247, 60-64. 
Visioli F, Bellosta S \& Galli C (1998b) Oleuropein, the bitter principle of olives, enhances nitric oxide production by mouse macrophages. Life Science 62, 541-546.

Visioli F, Caruso D, Galli C, Viappiani S, Galli G \& Sala A (2000a) Olive oils rich in natural catecholic phenols decrease isoprostane excretion in humans. Biochemical and Biophysical Research Communications 278, 797-799.

Visioli F \& Galli C (1998) The effect of minor constituents of olive oil on cardiovascular disease, new findings. Nutrition Reviews 56, 142-147.

Visioli F, Galli C, Bornet M, Mattei A, Patelli R, Galli G \& Caruso D (2000b) Olive oil phenolics are dose-dependently absorbed in humans. FEBS Letters 468, 159-160.

Willett WC (1997) Specific fatty acids and the risk of breast and prostate cancer, dietary intake. American Journal of Clinical Investigation 66, $1557 \mathrm{~S}-1576 \mathrm{~S}$. 